\title{
A vida e as formas da sociologia de Simmel
}

Lenin Bicudo Bárbara

Visão geral do problema

Georg Simmel pensou e repensou ao longo de boa parte de sua vida questóes concernentes aos fundamentos da sociologia, o que se liga à circunstância de seu período de maturidade intelectual coincidir com o primeiro momento de institucionalização da sociologia no mundo acadêmico alemão. Muito do que disse e escreveu sobre o tema inspirou ou interessou vários sociólogos e filósofos sociais posteriores: de Horkheimer a Park, de Schütz a Becker, de Elias a Goffman, de Mead a Luhmann. Dos registros do seu pensamento sobre o tema, o que temos hoje de mais importante são quatro textos publicados ao longo de quase três décadas, em 1890, 1894, 1908 e 1917. O primeiro, intitulado "Introdução: para uma epistemologia da ciência da sociedade" (Simmel, 1989a, pp. 115-138), é o capítulo inicial de seu livro sobre a diferenciação social; como notou Frisby, embora a posição de Simmel quanto à sociologia fosse então ambígua, já podemos detectar nesse texto as bases de seu projeto sociológico (cf. Frisby, 2002, p. 33). Se, em 1890, a intenção era apenas indicar o rumo para tal projeto, quatro anos depois Simmel tentaria pela primeira vez levá-lo a termo, com "O problema da sociologia” (Simmel, 1992a). Esse breve texto serviria de guia para o primeiro capítulo da Soziologie, sua principal obra como sociólogo, de 1908 (Simmel, 1992c, pp. 13-62). Simmel voltaria a publicar um texto do 
1. Este artigo é uma reelaboração da primeira seção do terceiro capítulo dessa dissertação, que desenvolvi como bolsista da Fapesp.

2. Essa conta se baseia nos dados apresentados em Bárbara (2012, p. 535, tabela 7). A contabilização foi feita segundo os critérios indicados nessa mesma obra.

3. Trata-se do começo de "Representaçōes individuais e representações coletivas". A essa altura do texto, Durkheim trata ambas as formas de representação como análogas, afirmando que elas mantêm a mesma relação com seu respectivo substrato - o que, longe de significar a redução de uma à outra, implica algum grau de independência dos termos análogos quanto a suas respectivas matérias (Durkheim, 1970, p. 14). Simmel conhecia bem essa concepção de analogia, presente em Aristóteles e mais tarde avaliada por Kant.

4. As "importaçōes conceituais" a que me refiro são metáforas. Este não é o espaço para esquadrinhar a relação entre metáfora e analogia, mas, ainda assim, é importante tratar rapidamente do assunto por meio de um exemplo. Quando Durkheim, portanto, importa o conceito de patologia da medicina para a sociologia, construindo a metáfora da patologia social, a inteligibilidade dessa importação depende de que se estabeleça uma comparação analógica entre o sentido desse termo no contexto semântico de origem do termo (podemos pensar aqui na medicina) e o seu sentido no contexto de chegada (a sociologia). gênero em 1917, quando seu interesse pela sociologia já não era o mesmo; trata-se aí de outro capítulo introdutório, bem decalcado do anterior, mas agora com o título "O domínio da sociologia" (1999, pp. 62-87; 2006, pp. 7-38). Nesse conjunto de textos, temos o que se pode chamar de programa sociológico de Simmel.

Neste artigo, proponho discutir esse programa, visando descortinar algumas das problemáticas que o nortearam. Para isso, pauto-me em uma leitura das analogias de que Simmel se serviu para formulá-lo.

$\mathrm{O}$ enfoque não é acidental. Como se sabe, Simmel recorria com frequência a comparações por analogia, nas suas mais variadas formas; em outro trabalho, mostrei como, além da presença numérica, as analogias de Simmel exercem uma miríade de funçóes distintas, centrais para o seu estilo de pensamento (cf. Bárbara, 2012, pp. 342-344) ${ }^{1}$. Além desse motivo geral, aponto como justificativa para esse enfoque uma segunda circunstância, ligada mais de perto ao núcleo temático deste artigo: o tratamento dado por Simmel à pergunta sobre os fundamentos da sociologia, tal como aparece em seu programa sociológico, pois uma leitura atenta desse programa permite identificar que se trata de um conjunto de textos especialmente densos em analogias. Para ilustrar o ponto, noto que o primeiro capítulo da Soziologie, em que temos a mais nuançada e extensa versão do programa simmeliano, conta com mais de sete analogias a cada dez páginas, enquanto no conjunto dos nove capítulos restantes do livro (em que o programa é posto em prática) essa frequência cai para menos de quatro por dez páginas ${ }^{2}$.

O peso das analogias para o programa sociológico de Simmel tem a ver, sem dúvida, com seu potencial heurístico - uma característica mais geral do raciocínio analógico, que não se limita ao caso desse autor. Em linhas gerais, pode-se dizer que essa característica faz da analogia um meio de orientação especialmente adequado para formular problemas em grande parte ainda não formulados, como era o caso de vários dos problemas básicos da sociologia na época de Simmel. Não por acaso, autores de resto muito diferentes dele recorreram ao mesmo expediente diante de situação semelhante. Um deles foi Durkheim, que não só comentou a utilidade da analogia para a sociologia, prescrevendo certas regras para seu uso adequado (cf. Durkheim, 1970, p. $13)^{3}$, como ainda recorreu a importações conceituais similares à analogia na "sua batalha para obter o reconhecimento do estatuto de ciência para a sociologia" (Lukes, 1984, p. 37) ${ }^{4}$.

$\mathrm{Na}$ Alemanha, Simmel se engajava na mesma batalha. Porém, se tanto ele como Durkheim recorreram a meios semelhantes para alcançar um fim 
semelhante, sem dúvida chegaram a resultados bem distintos. Isso é compreensível ao identificarmos a diferença por trás da semelhança genérica de seu objetivo comum: a ideia que um e outro tinham de "ciência", estatuto que almejavam para a sociologia, era decerto bastante diversa. (Não vou aqui me deter no confronto entre os dois, pois só evoco Durkheim para balizar uma análise da resposta específica de Simmel à pergunta sobre os fundamentos da sociologia. Mas creio que o leitor familiarizado com Durkheim notará as diferenças da sua concepção de ciência e do seu programa sociológico em relação aos de Simmel.)

O conceito de ciência a que Simmel busca fazer sua sociologia aderir é marcado por tensões e conflitos internos. De um lado, ele não deixa dúvidas quanto à sua vontade de "conferir ao conceito vacilante de sociologia um conteúdo unívoco, dominado por uma problemática segura quanto ao método" (1992c, p. 9). De outro lado, confessa que a principal ferramenta que prescreve ao analista social com pretensões científicas - a distinção entre a forma e o conteúdo da socialização - é "só uma metáfora” (Idem, p. 17), e ainda observa: "Nas questões do espírito, não é de todo raro [...] que isso o que precisamos designar com uma metáfora incontornável do fundamento não seja tão firme como a superestrutura construída em cima dele" (Idem, p. 30).

Essa ambiguidade se prende ao fato de que Simmel, "apesar dos seus esforços mais 'sistemáticos', na 'sociologia como ciência exata', [...] permaneceu sempre ligado a um momento cético, a uma skepsis que o impelia continuamente a uma posição que não se deixa definir sem mais através do método" (Waizbort, 2000, p. 589). Ou, para chegar ao mesmo ponto por outro caminho: o método sociológico, tal como formulado por Simmel, é no fundo uma maneira de ver a sociedade, pois proporciona certa imagem da realidade histórico-cultural.

A equação entre método e maneira de ver, evidente no programa sociológico de Simmel, exprime uma analogia mais fundamental entre visão e cognição, em torno da qual orbitam várias de suas analogias mais específicas. Para ele, fazer sociologia é fazer-ver a cultura humana do ponto de vista das interações de suas partes; é produzir uma imagem distintamente sociológica do mundo "do espírito"s.

Esse é, sem dúvida, um conceito vago de método, orientado a incrementar o conhecimento da realidade social, a fazer-ver o que ainda não se viu, mas sem delimitar ou predefinir um método mais substantivo ${ }^{6}$, mais à mão para ser aplicado pelo futuro sociólogo. Entretanto, por si só, essa observação não permite chegar ao cerne da questão. Mais revelador é que
5. Ver Simmel (1992c, p. 15), que define método como "um recurso da pesquisa para se chegar por um novo caminho aos fenômenos" culturais ou históricos, como a religião, a economia e o direito - logo após referir-se à sociologia como uma novo modo de observação a que se chegaria "nas assim chamadas ciências do espírito".

6. Durkheim faz uma crítica similar à demarcação da sociologia proposta por Simmel (cf. Durkheim, 2004, p. 84). 
7. Tirado do segundo capítulo de Lebenanschauung [Visão ou intuição da vida], de 1918.

8. Trata-se de um manuscrito não publicado por Weber em vida, ao que parece redigido em 1908 , por ocasiāo da publicação da Soziologie.
Simmel identificou justamente na analogia entre visão e cognição o ponto comum entre arte e ciência: "todos nós de fato somos, como seres que veem, pintores em fragmento ou embrião, assim como somos, como seres que conhecem, cientistas dessa mesma sorte" (1999, p. 270)7.

A fusão entre arte e ciência representa uma tendência do pensamento simmeliano que ele mesmo, ao atuar como sociólogo, buscou reprimir. Prova disso é que, para tentar fundamentar a sociologia, Simmel, como Durkheim, apoiou-se sobretudo em analogias de método com outras ciências. Ainda que também encontremos no seu programa sociológico analogias entre arte e sociologia, elas têm nele um peso bem mais pontual do que nos seus escritos filosóficos; basta pensar na centralidade da analogia com a arte em Filosofia do dinheiro (1900), de que ainda vamos tratar (cf. também Waizbort, 2000, pp. 82-87).

Por fim, apesar de seu esforço, tal tendência mostrou-se inevitável. Nada simboliza isso melhor do que o caráter visual e plástico do estilo simmeliano, para o qual o ensaio é forma mais adequada, e que também aparece tanto no uso de analogias ilustrativas e exemplos anedóticos - bastante presentes na Soziologie - como nas gesticulações que fizeram sua fama como professor (cf. Idem, pp. 571-588).

Comentando um desses gestos, Cohn contrasta esse caráter visual e contemplativo do estilo simmeliano com a atitude mais ativa de Weber, ao "questionar-se sobre os fundamentos da seleção e construção" do conceito sociológico (Cohn, 2003, p. 68). De fato, parte de suas críticas a Simmel se volta ao caráter demasiado plástico e flexível de seus conceitos, como o de interação. Mesmo ao reconhecer suas contribuições como sociólogo, Weber $(1991, \text { p. } 11)^{8}$ enfatiza que o interesse último de Simmel não seria bem o da ciência, de modo que esta seria uma espécie de produto secundário, como se o incremento cognitivo a que ele ainda assim chegou não tivesse sido alcançado pela via científica, ou seja, com método. Sobre isso, uma comentadora avalia que Weber não teria sido capaz de elogiar Simmel como sociólogo, mas apenas como artista (cf. Nedelmann, 2004, pp. 86-88).

Seja como for, Weber também notou que a analogia era "um meio que Simmel considerava útil para os seus fins" (Weber, 1991, p. 11). Se, como vimos, o conhecimento que Simmel buscava era um fazer-ver, se o que ele chama de método era na verdade um meio para expor certa fração do real, então a técnica preferida de Simmel para isso era mesmo a analogia.

Essa preferência fica clara com a leitura de "Das Problem der Sociologie", texto de 1894 sobre o problema da sociologia, cujo objetivo é demarcar o campo 
legítimo de atuação da sociologia como ciência. O texto tem sete parágrafos e, do segundo em diante, Simmel elabora, em cada um deles, ao menos uma analogia entre a sociologia e outro domínio científico, expondo de analogia em analogia vários aspectos da "nova ciência". Em seguida, ele parte de uma distinção entre a forma e a matéria da sociedade para propor que a sociologia se ativesse ao estudo das formas de interação recíproca em que se constitui a sociedade, às quais se refere ora como formas, ora como processos de socialização (Vergesellschaftung). Para expor essa proposta, Simmel estabelece uma série de analogias entre a sociologia, de um lado, e a psicologia, a geometria e a economia, de outro (cf. Simmel, 1992a, pp. 54-59; Bárbara, 2012, pp. 199-200).

Mas ele não recorre à analogia como mero meio de exposição, como expediente retórico, no sentido mais vulgar do termo9: para ele, método e exposição estão tão imbricados que, na prática, a separação analítica entre ambos perde sentido. Pois, se as analogias são formas de expor, o que Simmel expõe com elas não deixa de ser conhecimento, e, nesse ato, o meio de expor torna-se um meio para conhecer. Compreendemos isso ao ponderar que Simmel aderiu particularmente a essa técnica em parte por considerá-la um recurso necessário para conceber e formular problemas novos e para dar à ciência uma linguagem e um vocabulário mais adequados do que aqueles de que se dispunha para enquadrar certas questôes até então; por isso, a analogia tem real valor cognitivo, pois permite conhecer algo que não se conheceria de outro modo.

Já podemos detectar essa função cognitiva em "Das Problem der Sociologie”, de 1894, se nos concentrarmos em suas analogias de método - ou melhor, nas analogias da observação metódica, para usar a expressão mais tarde escolhida por Simmel (1992c, p. 34) para esse tipo de analogia. Mas, para esse fim, considero mais produtivo um enfoque nas duas analogias de método que Simmel passa para o primeiro plano da versão mais densa e madura de seu programa sociológico - uma geométrica, outra biológica. Vamos a elas.

\section{As formas da sociedade}

De modo geral, a exposição dos vários aspectos do problema da sociologia no texto de 1894 passa uma imagem ainda bem simples e congruente, que não parece comportar grandes tensões internas. Isso já não pode ser dito da versão de 1908 do programa sociológico de Simmel. Mostrarei como
9. No entanto, seria possível pensar a analogia nesse registro, caso se operasse com um conceito de retórica mais sofisticado que aquele usado para desqualificar esta ou aquela ideia como "pura retórica". É o caso da abordagem de Blumenberg (1987), leitor de Simmel, sobre o problema. 
10. Frisby (1992, p. 40) nota que as críticas de Simmel a essa sociologia genérica, assentada num conceito substantivo (e não "interativo") de sociedade, ecoava as críticas de Dilthey a Comte, a Spencer e à filosofia da história alemã. Em parte, Simmel também criticou alguns aspectos da própria posição, assumida no seu livro sobre a diferenciação social, sob a influência da Spencer e dos seus professores na academia alemã - livro em que, não obstante, já ensaiava o passo para a sua sociologia "científica". as duas principais analogias de método que ele formula na introdução à Soziologie remetem a dois problemas distintos com que a sociologia teve de lidar. O primeiro, que dá sentido a uma série de analogias entre sociologia e geometria (e que, para além dessa analogia, Simmel tenta resolver propondo à sociologia estudar o que chama de formas de socialização), surge em um nexo argumentativo peculiar, que reconstruo a seguir.

Grosso modo, o conceito de forma de socialização é uma resposta à questão sobre qual seria o objeto específico da ciência da sociedade. O que confere sentido à pergunta é a vontade de identificar a sociologia como forma de conhecimento equivalente à geometria e à biologia, de buscar legitimá-la como ciência - vontade cuja realização se impunha como necessária para viabilizar sua institucionalização no universo acadêmico. Este era, portanto, um problema da maior importância para autores como Simmel e Durkheim. Assim, ao contrário do aspecto do problema da sociologia tratado por meio da analogia de método com a biologia, esse primeiro aspecto teve grande destaque no texto de 1894. Seu tratamento ao longo da Soziologie é em boa medida apenas um aprimoramento da posição inicial de Simmel, que desde o princípio tratou de deixar claro que a sociologia só poderia se apresentar como ciência se fosse capaz de satisfazer certas condições. Entre elas, uma das que mais o preocupava dizia respeito à definição de seus limites, à identificação de um domínio novo e exclusivo de atuação, irredutível a todas as ciências então estabelecidas - o que inclui não só a matemática e biologia, mas, sobretudo, a psicologia e a história, mais próximas da sociologia e, por isso, mais relevantes quando se trata de definir os seus limites.

Como alguns de seus contemporâneos, Simmel entendia que as demais propostas para uma sociologia científica disponíveis em seu tempo, como as de Comte e Spencer, falhavam justamente por perderem de vista tais limites, tornando-se uma espécie de ciência humana genérica ${ }^{10}$. Simmel assim formula o ponto a certa altura do primeiro capítulo da Soziologie:

Contribui para essa representação da sociologia como ciência de tudo que é humano em geral a circunstância de que ela era uma nova ciência que, por isso, atraía para si toda a sorte possível de problemas ainda não devidamente situados - como um domínio recém-descoberto acaba se tornando num primeiro momento um Eldorado para as existências sem pátria e desenraizadas: a indeterminação de partida incontornável e o não resguardo das fronteiras conferem a qualquer um o direito de ali se acomodar (Simmel, 1992c, p. 14, grifo meu). 
Temos aí uma analogia entre o surgimento de uma ciência e o "descobrimento" de um novo território geográfico, que, aliás, não é um lugar qualquer, visto que repleto de riquezas e construções em ouro maciço, na imaginação dos viajantes e conquistadores europeus. Simmel rejeita essa postura colonizadora do sociólogo, propondo que a sociologia, se se pretende ciência, não pode almejar abarcar tudo o que se passa na sociedade, precisando ater-se a um modo específico de abstração.

Não basta, no entanto, identificar tal objetivo e propor que a sociologia deveria operar uma abstração particular da realidade; é preciso ainda definir os meios para alcançá-lo, propor como ela deveria fazer isso. Nesse sentido, Simmel prescreve que o sociólogo considere o mundo social não como um todo, mas como resultado de um sem-número de processos de interação, como uma série de formas de socialização. E é para ilustrar esse "como" que ele recorre às analogias.

Já em 1894, Simmel apoiava-se principalmente em uma analogia com a psicologia para ilustrar esse ponto; formulava de passagem também uma analogia com a geometria, só para reforçar a lição. Catorze anos depois, priorizou essa analogia em seu argumento, o que indica que ela então lhe pareceu um meio especialmente adequado para comunicar o caráter formal de sua sociologia, implícito na prescrição metodológica de considerar o mundo social como forma.

Deve-se ter em mente que Simmel só recorre à analogia de método com a geometria para expor a distinção entre a forma e o conteúdo da socialização, que marca o que há de exclusivo no "método" sociológico por ele proposto, e assim responder qual é o lugar da sociologia entre as ciências; essa falta de atenção já levou comentadores como Freyer e Aron a reduzir a sociologia de Simmel a uma "geometria do mundo social", em uma leitura demasiado literal da analogia (cf. Bárbara, 2012, pp. 207-220). A questão era, por sua vez, pautada pela crítica de Simmel a uma sociologia genérica, de modo que, fora desse nexo, a analogia com a geometria já não faz sentido ${ }^{11}$.

Consideremos um dos momentos em que Simmel formula sua analogia com a geometria:

O conceito de sociedade abrange dois significados que devem ser mantidos, para a discussão científica, fortemente demarcados um do outro. De um lado, ela é [...] o material humano socialmente formado, tal como constituído pela realidade histórica como um todo. Mas, de outro, "sociedade" é também a soma das formas de relação que possibilitam que se faça, a partir de indivíduos, a sociedade na primeira
11. Assim, quando Simmel retomou essa analogia em 1917, fez isso no primeiro dos dois parágrafos dedicados a expor a sua sociologia "pura”, cujo objetivo seria investigar o que é exclusivamente social na sociedade, numa clara oposição ao que ele aí chama de sociologia geral (cf. Simmel, 1999, pp. 82-84; 2006, pp. 32-35). Ainda voltarei a isso; neste ponto, interessa que, nove anos após a Soziologie, o contexto argumentativo da analogia geométrica é o mesmo. 
acepção. Assim também, de um lado, chamamos de "esfera" uma matéria formada de certo modo, mas, de outro, na acepção matemática, também a mera figura ou forma que possibilita que se faça, a partir da mera matéria, a esfera na primeira acepção. Quando se fala das ciências da sociedade naquele primeiro sentido, toma-se como seu objeto tudo o que se passa na sociedade; a ciência da sociedade na segunda acepção toma como objeto as forças, as relações e as formas pelas quais os homens se socializam e que [...] constituem a "sociedade" sensu strictissimo (Simmel, 1992c, p. 23).

A sociologia na primeira acepção é a sociologia genérica que Simmel critica, que se orienta à "realidade histórica como um todo" e que pretende tomar como objeto "tudo o que se passa na sociedade". Esse é um ponto crucial para Simmel, para quem uma forma de conhecimento orientada à totalidade não é ciência, pois esta envolve um modo particular de observação, opera com um recorte, uma seleção, um aspecto do todo. Assim, a sociologia só teria lugar entre as ciências se abandonasse a pretensão de abarcar o todo da história, passando a fracionar e racionalizar esse todo que, como tal, somos incapazes de observar.

Note-se como não se trata aí de uma analogia substantiva entre a sociedade e o espaço, mas sim de uma analogia cujo foco é o modo como o sociólogo e o geômetra "veem" o seu respectivo objeto - e é esse núcleo visual da analogia entre sociologia e geometria que faz dela uma analogia de método, nos termos de Simmel. Mesmo essa analogia espacial está, portanto, combinada àquela analogia elementar entre visão e cognição a que me referi, e que agora vem destacar o caráter fragmentário e seletivo da cognição humana: assim como somos incapazes de olhar para todos os lados ao mesmo tempo, somos também incapazes de compreender a realidade inteira à nossa volta. Essa insuficiência seria tomada como ponto de partida de toda ciência, que extrairia tanto conhecimento quanto possível de cada recorte específico operado sobre a realidade - e a analogia de método com a geometria é mobilizada para ilustrar como esse recorte deveria ser feito no caso da sociologia.

As analogias geométricas que Simmel formulou para ilustrar o que concebia como método sociológico se baseiam na sua leitura de Kant, pois, quando fala em geometria, no fundo é à concepção kantiana de geometria que ele se refere. Kant também é a referência para a série de problemas básicos da sociologia que lhe confere sentido. A iniciativa em demarcar com rigor o lugar da sociologia entre as ciências, a separação entre forma e conteúdo, a grande frequência das analogias espaciais, a eventual designação 
da sociologia sensu strictissimo como sociologia pura: isso tudo corresponde à imagem que Simmel fazia de Kant. Basta-nos, nesse contexto, chamar a atenção para o que ele uma vez escreveu de que a "fórmula para a essência kantiana" consistia em estabelecer limites, e isso na mesma obra em que designou Kant como "cofundador e partidário do espírito científico moderno" $\left(\right.$ Simmel, 1995, pp. 138 e 164) ${ }^{12}$. Esta é, em parte, a razão de a analogia com a geometria fazer tanto sentido para Simmel: ela parece fornecer uma saída imanente para o problema do lugar da sociologia entre as ciências, concebido "kantianamente", afinal.

Como vimos, a solução para esse problema implicaria demonstrar que a sociologia é capaz de sondar um espectro da realidade que não poderia ser sondado de outro modo, o que, para Simmel, depende da identificação do que, na sociedade, seria "pura" sociedade. A isto ele deu o nome de formas de socialização, que são como as formas puras da geometria segundo Kant. Ou seja, embora não tenhamos nenhuma experiência particular de uma esfera pura, somos capazes de intuir a "esfericidade" de uma esfera real, de estudar suas propriedades, de entender como suas partes se inter-relacionam - enfim, de fazer geometria. Grosso modo, a geometria é possível, para Kant, porque toma como objeto isso que ele chama de intuições puras do espaço, nas quais as "formas" do espaço em geral são pensadas de maneira independente de toda "matéria" ou "conteúdo" particular. Para Simmel, a sociologia deve, analogamente, buscar separar as formas de socialização dos conteúdos particulares da vida humana.

Essa separação é, por sua vez, o que lhe permite identificar a sociologia como ciência. Este é o ponto: a analogia com a geometria serve para fazer-ver o que confere cientificidade à sociologia; nesse sentido, ela faz parte da estratégia mobilizada por Simmel para incorporar a sociologia ao conjunto das ciências. Simmel (1992c, pp. 27-28) foi claro ao tratá-la como simples meio para tal fim. Ao restringir desse modo o sentido de sua analogia, ele já prepara o terreno para identificar as limitações desta, mas não antes de desdobrá-la mais um pouco:

É só dessa maneira que se pode conceber o que, na sociedade, é efetivamente "sociedade”, assim como a geometria só determina o que, nas coisas espaciais, é sua real espacialidade. [...] A sociologia está para as demais ciências especializadas como a geometria está para as ciências físico-químicas da matéria: considera a forma pela qual a matéria em geral se converte em corpos empíricos (Idem, p. 25).
12. Trata-se de Kant und Goethe. 
A analogia de método entre sociologia e geometria é exposta aqui de modo bem claro e condensado. Desdobrando-a ponto por ponto, Simmel parte de sua prescrição em se ater ao que é propriamente social na sociedade para em seguida apontar, ainda por analogia, como isso indica a posição da sociologia diante das demais ciências do espírito - posição que informa a tarefa específica da sociologia entre elas. As "ciências especializadas" a que Simmel se refere são específicas num sentido diverso ao que ele prescreve à sociologia: sua exclusividade deriva de um tema particular, não de certo modo de abstração. Cada um desses temas corresponde ao que Simmel chamou de sistemas de interesse da cultura - a religião, a política, o direito, o trabalho, a ciência, a arte, a vida íntima etc. -, que para ele sem dúvida se passam na sociedade, mas cuja natureza não é apenas sociológica, do mesmo modo que os eventos físico-químicos ocorrem no espaço, sem por isso formarem o objeto sui generis da geometria na acepção kantiana .

Após estabelecer tais comparações, Simmel, de modo bem característico, volta a tratar dos limites dessa analogia, declarando que ela não vai além de certo problema fundamental da sociologia. Mas ele não se contenta com essa declaração, revirando a mesma analogia até detectar mais precisamente o seu limite:

É como na demonstração de uma proposição geométrica feita com uma figura desenhada num plano, de uma contingência e crueza inevitáveis. Mas o matemático pode contar com que o conceito da figura geométrica ideal seja conhecido e atuante, considerando-o o único sentido essencial desses traços de giz ou de tinta. Já na sociologia não se deve partir do pressuposto correspondente; não há como submeter ao jugo da lógica a tarefa de arrancar, da totalidade complexa dos fenômenos, o que a pura socialização de fato é (Idem, p. 29).

Nesse ponto, a analogia entre sociologia e geometria já não se aplica ou seja, há certo aspecto do "problema" da sociologia que ela não permite ilustrar. A diferença em jogo pode ser assim delineada: enquanto a geometria pode operar em um universo contínuo, homogêneo, unívoco e transcendental, a sociologia seria obrigada a operar em um mundo descontínuo, heterogêneo, equívoco e imanente. Trata-se da mesma diferença com que Simmel se depara no excurso do primeiro capítulo da Soziologie, ao comparar a natureza na acepção kantiana com a natureza que interessa ao sociólogo (cf. Idem, pp. 42-47; 2013, pp. 653-658). Por isso, se a analogia com a geometria fornece um ponto de acesso à sociologia simmeliana, não a esgota: 
as mesmas formas de socialização que, vistas de certo ângulo e para certos fins - apresentar a sociologia como ciência - são análogas às geométricas, quando vistas de outro aparecem como formas de vida.

Esse outro aspecto põe a questão em termos totalmente alheios a Kant. Ora, o que Simmel trata na passagem citada como uma mera vantagem da geometria diante da sociologia é, para Kant, o pressuposto mais básico da geometria, aquele que a torna possível. Levando ao extremo o que Simmel propõe ao revirar a analogia geométrica, ele nega, ainda que indiretamente, que a sua sociologia seja uma ciência tão bem delimitada como ele pretendia apresentá-la. Com efeito, no mesmo parágrafo de que foi tirada a citação anterior, afirma que não há, até onde consegue ver, "nenhum método efetivo e seguro para extrair o sentido sociológico daqueles fatos complexos, cuja realização é mediada por seus conteúdos" (Idem, p. 28).

Nessa última reformulação negativa da analogia geométrica, detectamos o núcleo de uma outra série de problemas que Simmel teve de enfrentar, para a qual a analogia geométrica não basta, que diz respeito à complexidade do mundo social. Ele tratou dessas questóes ao especular sobre a vida da sociedade, uma de suas peculiaridades que, uma vez assimilada no plano da explicitação teórica, daria à sociologia simmeliana um rumo bem diverso daquele identificado pelos autores que levaram ao pé da letra suas analogias com a geometria - como Freyer, que, ignorando uma série de analogias que Goffman não haveria de ignorar, classificou o projeto de Simmel como "a mais completa ciência do logos", obstinada em buscar "formas imutáveis, passíveis de análise e ordenação sistemática" (Freyer, 1944, pp. 74-75).

\section{A vida da sociedade}

Das contribuições sui generis de Simmel para a sociologia, talvez as mais marcantes sejam as que tratam das formas mais voláteis de socialização, como o segredo, o adorno, o jogo, a fidelidade. Foram elas que fizeram a fama de Simmel como fundador da microssociologia.

Mas houve um tempo em que Simmel não identificava nada disso como objeto efetivo da sociologia. No primeiro dos textos que compõem seu programa sociológico - a introdução ao livro sobre a diferenciação social, de 1890 -, ele já operava com noções similiares ao conceito de forma de socialização, mas sem chamá-las por esse nome. Ele então reconhecia que "uma sociedade se formaria até por duas pessoas, entre as quais se passa 
13. Numa longa nota de rodapé, Simmel (1992a, pp. 57-58) sugere que a sociologia deveria tratar de fenômenos que "parecem ser de natureza individual", citando como exemplo disso o papel das associaçōes secretas. É sugestivo que esse texto seja o único do seu programa sociológico sem analogias biológicas, como se nesse momento fosse inconveniente chamar a atenção para os problemas relativos à "vida da sociedade", que ele ainda não sabia resolver muito bem. apenas uma relação efêmera” (1989a, p. 133) - ou seja, que, a princípio, a ideia de que a sociedade resulta da interação de suas partes possibilitaria tomar como objeto de uma sociologia mesmo as formas mais efêmeras de socialização. Logo após afirmar isso, no entanto, ele descartava tal possibilidade, considerando-a inviável na prática:

Talvez se possa ver a fronteira do ser propriamente social lá onde a interação das pessoas umas com as outras não só se constitui num estado subjetivo ou na ação dessas pessoas, mas também onde traz à tona uma estrutura objetiva, que tem certa independência diante das personalidades singulares que nela tomam parte. [...] É aí que está a sociedade, é aí que a interação se concretizou em um corpo - um corpo que identifica aquela interação como algo social, distinguindo-a da que desaparece com os sujeitos diretamente em jogo e com seu comportamento momentâneo (Idem, pp. 133-134).

Assim, Simmel remete o estudo das formas efêmeras de relação (isto é, das formas de interação que ainda não ganharam um "corpo" propriamente social) ao âmbito da psicologia. A imagem do corpo como forma de vida da sociedade já aparece, mas só como analogia substantiva entre vida e sociedade, e não como analogia de método.

Tal formulação revela um problema que o preocupou por muito tempo: como conceber as formas efêmeras de socialização? Se, neste texto de 1890, Simmel relegava o problema à psicologia, apenas quatro anos depois já não sugeria descartá-los da consideração sociológica, embora tampouco oferecesse indicações precisas de como tratá-las ${ }^{13}$. Para formular esse "como" e assim integrar o estudo das formas voláteis de socialização à Soziologie, Simmel recorreu à analogia de método com a biologia.

Essa analogia ocupa um extenso parágrafo do primeiro capítulo da Soziologie - um parágrafo repleto de expressões como "por assim dizer" e "como que", ou seja, de figuras de linguagem, de que Simmel se serve para indicar o caráter aproximativo e provisório de suas comparações (cf. Bárbara, 2012, p. 233). Vejamos como Simmel reconstrói a posição que ele mesmo assumira em 1890, dessa vez para criticá-la:

Em geral, a sociologia limitou-se, de fato, àqueles fenômenos sociais nos quais as forças de interação já estão cristalizadas do lado de fora dos seus suportes imediatos, ao menos como unidades ideais. Os Estados e as associações sindicais, as ordens sacerdotais e as formas familiares, [...] a formação de classe e a divisão industrial 
do trabalho - estes e os grandes órgãos e sistemas do gênero parecem compor a sociedade e ocupar a esfera de sua ciência (Simmel, 1992c, pp. 31-35) $)^{14}$.

Esses "grandes órgãos e sistemas" correspondem precisamente àquele corpo em que se concretizava a interação, no qual Simmel via, em 1890, "a fronteira do ser propriamente social”. Nessa época, Simmel já dava claros indícios de sua vontade de investigar essas formas de socialização - o que faltava eram os meios conceituais para realizar essa vontade.

Se, em 1908, Simmel afirmava a importância que as formas mais voláteis de socialização teriam para reprodução da vida social - bem como a necessidade imposta ao sociólogo de, com vistas a isso, ao menos tentar apreendê-las em conceitos -, é porque considerava ter encontrado tais meios. Note-se que, assim como a analogia geométrica, também a biológica apenas comunica ou permite formular a solução adotada por Simmel para lidar com certo problema mais fundamental. O que aconteceu de decisivo entre 1894 e 1908 não foi a formulação dessa analogia, mas sim o trabalho em torno da sua Filosofia do dinheiro ${ }^{15}$, que lhe permitiu aprimorar uma técnica para lidar com mais desenvoltura com as formas efêmeras de socialização. O resultado desse trabalho é resumido na máxima: ver no singular o universal, olhar para os laços micro-macro. E é para demonstrar o análogo sociológico dessa técnica - ilustrada como procedimento artístico em Filosofia do dinheiro - que Simmel evoca a biologia:

Além dos fenômenos perceptíveis de longe [...] há um número imenso de formas menores de relação e de modos de interação entre as pessoas, em casos singulares aparentemente insignificantes, mas que [...] com efeito realizam a sociedade como a conhecemos. A limitação aos primeiros equivale aos inícios da ciência do interior do corpo humano, que se limitava aos grandes órgãos, claramente circunscritos: o coração, o fígado, o pulmão, o estômago etc., e que desprezou os tecidos inumeráveis popularmente não nomeados ou não conhecidos, sem os quais aqueles órgãos mais nítidos jamais poderiam ter resultado em um corpo vivo (Simmel, 1992c, p. 32).

Estamos aqui diante da mesma analogia da sociedade como forma de vida, como unidade dinâmica que resulta da interação de suas partes; no entanto, a ênfase não recai agora na sociedade e no organismo como tais, mas no modo como o cientista observa a realidade. Não por acaso, na sequência do argumento, Simmel se refere ao estudo de tais formas de socialização
14. A referência abarca todo o parágrafo, traduzido em Waizbort (2000, pp. 92-95). Sirvo-me dessa tradução, com algumas alteraçōes. O mesmo ocorre para a citação abaixo.

15. A segunda edição dessa obra é de 1907, o mesmo ano do ensaio de Simmel sobre a sociologia dos sentidos, em que ele formula pela primeira vez a analogia de método aqui exposta. 
16. Apesar desse núcleo, a analogia de método com a biologia ainda toca em outros pontos. A certa altura, por exemplo, Simmel fala em "aplicar o princípio dos efeitos infinitamente múltiplos e infinitamente pequenos justamente ao caráter sincrônico da sociedade, tal como se mostrou eficaz nas ciências diacrônicas da geologia, da teoria biológica da evolução e da história” (1992c, pp. 33-34). Na teoria da evolução de Darwin - uma das ciências diacrônicas a que se refere - esse princípio implica que as transformaçóes das formas de vida devem ser tratadas como produto de um acúmulo de pequenas mudanças ao longo de grandes períodos de tempo. Ainda nesse caso, não "vemos" tais mudanças acontecerem pois as consideramos muito parcialmente: o tempo de nossa vida é muito pequeno se comparado ao tempo da evolução das espécies.

17. Isso porque as inovações técnicas de que depende o incremento do conhecimento do real podem se dar quer na forma da confecção de novos artefatos culturais, como o microscópio, quer na forma de construçōes e esquemas conceituais (ver exemplo na nota anterior), o que sugere uma analogia, hoje bastante popular, entre a teoria de Darwin e a epistemologia, que Simmel formula explicitamente em um ensaio de 1895 (cf. Simmel, 1992c, pp. 62-74), cujo conteúdo seria mais tarde incorporado a Filosofia do dinheiro.

18. Evidentemente, ligado ao problema bem menos transcendental da inserção da sociologia como atividade institucionalizada no mundo acadêmico alemão. Esse ponto já está bem assentado na literatura sobre Simmel; ver, por exemplo, Waizbort (2000, pp. 509-534). como uma espécie de microscopia social, sendo esse o núcleo de sua reformulação da analogia biológica ${ }^{16}$. O microscópio permitiu "a percepção de novos segmentos do real” (Waizbort, 2000, p. 96), o que, se não bastou para eliminar a contingência e a crueza inevitáveis do nosso conhecimento sobre o interior do corpo humano, permitiu um incremento sem igual do conhecimento sobre ele. Simmel, claro, apropria-se do microscópio por ana$\operatorname{logia}{ }^{17}$ : sugere que devemos observar as formas mais voláteis de socialização buscando detectar como elas permitiriam a existência da sociedade empírica, como contribuiriam para que as formas de vida surgissem, permanecessem, transformassem-se ou eventualmente desaparecessem.

A analogia de método com a biologia (aliás, mantida na versão de 1917 de seu programa sociológico, ao contrário da analogia com a geometria, que então retornaria ao segundo plano) é o que, ao lado do excurso do primeiro capítulo do livro, permite enquadrar no plano da explicitação teórica vários dos capítulos e excursos que compóem a Soziologie, como o capítulo sobre o segredo e o excurso sobre a sociologia dos sentidos. Como sugeri, Simmel emprega essa analogia para comunicar sua resposta ao problema da complexidade da vida social, concebido já desde 1890 na chave de uma analogia entre a sociedade e a vida.

Eis o problema, agora formulado fora dessa chave: as formas efêmeras de socialização parecem impor dificuldades especiais para serem compreendidas, como se nossos dedos não fossem delicados o bastante para desembaraçar os fios mais finos do real. Elas são, em uma palavra, complexas, e em geral só dizemos que algo é complexo ou complicado quando já não somos mais capazes de defini-lo de maneira inequívoca. Simmel não fugiu a essa regra: considerava esse tipo de complicação característica da sociedade empírica, constituída na prática como um emaranhado de formas dinâmicas de socialização - que já não são formas puras, como as estudadas pela geometria, mas sim cruas e imperfeitas, como aqueles círculos desenhados com giz, cujos "defeitos" ou modulações o sociólogo, ao contrário do matemático, não pode ignorar (cf. Cohn, 1998).

Assim concebidas, as analogias com a geometria e com a microscopia funcionam como duas estratégias complementares mobilizadas para educar o olhar sociológico. Elas funcionam, para resumir, como formas de exposição para as soluçôes provisórias de dois dos problemas básicos com que Simmel teve de lidar na tentativa de fundamentar a sociologia: de um lado, o problema "kantiano" do seu devido lugar na confederação das ciências ${ }^{18}$; de outro, o problema "darwiniano" da complicação e da contingência próprias 
ao universo social ${ }^{19}$. Simmel, ao atuar como sociólogo, comunica a solução desses problemas por meio de sua analogia de método com a biologia.

Mas, como se sabe, o papel de sociólogo não foi o único que ele desempenhou ao longo da vida.

\section{Simmel na fronteira da sociologia}

Em 1917, Simmel publicou o último texto em que retomaria as questōes aqui discutidas. $\mathrm{O}$ texto contém poucas novidades em relação aos anteriores; entre elas, está sua conhecida divisão da sociologia em três áreas: a geral, a pura e a filosófica. Como Frisby (1992, p. 35) notou, essa proposta é tardia, distante do período de maior envolvimento de Simmel com a sociologia. Acrescento a isso que, para Simmel, abrir espaço para uma sociologia geral significava fazer uma concessão ao tipo de sociologia que ele mesmo criticara nos demais textos de seu programa filosófico e que, não obstante, estava entranhado no próprio trabalho de 1890 sobre a diferenciação social. Significava assim recuar diante das inúmeras críticas que recebeu por restringir demais o campo de atuação da sociologia, a que Durkheim (2004, pp. 92-94) aliás deu voz ${ }^{20}$.

Isso fica claro se considerarmos os exemplos que Simmel selecionou, em meio à sua vasta produção como sociólogo, para ilustrar o que seria sociologia geral e o que seria sociologia pura. O segundo capítulo de Questôes fundamentais da sociologia, que exemplifica a sociologia geral, é em parte decalcado do quarto capítulo do seu livro sobre a diferenciação social, contendo até alguns trechos que permaneceram inalterados de um livro a outro por 28 anos. Se Simmel serviu-se de suas ideias de juventude para exemplificar o que é a sociologia geral, escolheu, para exemplificar a sociologia pura, um de seus últimos trabalhos originais como sociólogo: o ensaio sobre a sociabilidade, baseado em sua conferência para o primeiro congresso da Sociedade Alemã de Sociologia. De resto, numa nota de rodapé ligada à explicação do que seria a sociologia pura, Simmel (1999, p. 84; 2006, p. 35) remetia o leitor à sua Soziologie, identificando as investigações ali contidas com essa vertente "exata" da sociologia ${ }^{21}$.

Algo diverso ocorre se consideramos a distinção entre essas duas vertentes da sociologia e a vertente filosófica: neste caso, a distinção é mais uma espécie de explicitação de uma característica constitutiva do estilo simmeliano - algo que Simmel nunca pretendeu superar - e se torna mais relevante para compreendermos seu pensamento.
19. Em minha dissertação, exploro com mais detalhes a recepção simmeliana de Darwin, que é mais intrincada e profunda do que pude aqui reconstruir (cf. Bárbara, 2012, pp. 44-68 e 221-227).

20. Ainda que aceite a crítica a uma sociologia genérica tal como formulada por Simmel, Durkheim propõe que certo tipo de sociologie générale é perfeitamente justificável. A sociologia geral defendida por Simmel em 1917 não é exatamente a que ele sempre criticou, mas uma variação dela - aliás, formulada com uma boa dose de ambiguidade.

21. Diga-se que, apesar dessa intenção, Soziologie contém vários traços do que ele chamaria em 1917 de sociologia geral, o que testemunha os embaraços dessa distinção. 
22. A imagem de uma sociologia genérica que atua como um "império mundial" aparece em Simmel (1992a, pp. 52-53).

23. O que é só um caso particular de uma conclusão mais geral da minha pesquisa de mestrado, na qual proponho que é necessário para Simmel levar a cabo seus projetos, dos quais a sociologia é só um caso, nunca esta ou aquela analogia, mas o procedimento analógico como tal, o ato de estabelecer e combinar várias analogias (cf. Bárbara, 2012, pp. 245-246 e 342-344).

24. A abordagem de Simmel desse tipo de questão foi bastante discutida em minha dissertação, sob vários aspectos; no que toca mais diretamente ao enfoque deste artigo, ver Bárbara (2012, pp. 239-243).
Isso nos permite retomar um ponto importante. Mostrei como a analogia de método entre sociologia e geometria se baseava em uma analogia mais geral entre espaço e cognição, presente não só na própria construção do problema para o qual a analogia geométrica ilustra a solução, mas também na descrição da sociologia como domínio exclusivo do conhecimento, que deveria assim evitar aquela postura "imperialista" da sociologia geral ${ }^{22}$. A mesma analogia básica aparece no prefácio de Filosofia do dinheiro, também partindo de uma determinação do lugar da filosofia - que Simmel, claro, direciona em um sentido diverso daquele prescrito à sociologia (cf. Simmel, 1989b, pp. 9-10; Bárbara, 2012, pp. 303-310).

Além disso, mostrei que a analogia geométrica deve ser concebida na sua relação com a biológica ${ }^{23}$ - esta, assentada em uma analogia mais geral entre vida e cognição, que permite destacar o aspecto contingente do mundo social, apresentá-lo como resultado de um processo contínuo em que cada uma de suas partes, mesmo a que parece mais insignificante, condiciona as demais. Essa analogia mais elementar também se mostra quando Simmel destaca o caráter apenas provisório de suas investigações sociológicas (cf. Simmel, 1992c, pp. 64-65; Bárbara, 2012, pp. 260-262); quando enche alguns trechos de uma obra proposta como científica de expressões como "por assim dizer" e "como que"; quando sugere que a sociologia, como toda ciência, precisará buscar seus fundamentos sempre outra vez - outro modo de dizer que nunca irá encontrá-los. Essa valorização do caráter provisório e aproximativo de sua sociologia, em particular, e da ciência, em geral, está para ele ligada à sua desconfiança diante de todo conhecimento pretensamente definitivo; como Weber, Simmel sempre enfatizou o caráter seletivo e fragmentário do conhecimento humano, resultante de que sua realização envolve a tentativa de abarcar uma "realidade infinita" com os recursos de um "espírito humano finito" (cf. Weber, 2004, p. 44) ${ }^{24}$.

Se é verdade que Weber se viu diante do mesmo problema, também é certo que algo o perturbava na solução simmeliana. Para elucidar essa questão, chamo a atenção para que esse segundo conjunto de problemas elementares da sociologia tratados por Simmel fora, na Filosofia do dinheiro, resolvido com outra analogia básica: a da arte. A mesma estratégia de flexibilidade que afinal desponta na sociologia simmeliana está no núcleo de sua proposta filosófica, sendo também o terreno em que ele considerava legítimo conjugar arte e ciência. Por isso, apesar de ter mais sentido que a distinção anterior, também a separação entre a sociologia pura e a filosófica, como apresentada em Questôes fundamentais da sociologia, tem algo 
de traiçoeiro: só na superfície a primeira não é também filosófica. Se, para expor o seu método sociológico, Simmel tenta reprimir a fusão entre ciência e arte, tratando como secundárias as analogias entre a sociologia e a arte e articulando no primeiro plano do argumento uma analogia geométrica (baseada em uma analogia mais geral entre espaço e cognição) com uma biológica (entre vida e cognição), ainda assim a analogia com a arte entrou de contrabando na sua sociologia pela ênfase visual que informa sua concepção do método sociológico.

Eis o que perturbava Weber. Este apoiou mais do que Durkheim o tipo de estratégia flexível de conceituação adotado por Simmel, uma vez que também concebia o trabalho conceitual como mera ferramenta para incrementar o conhecimento acerca da realidade; contudo, tanto Weber como Durkheim foram bem mais longe em prescrever um método substantivo, prático e replicável para o futuro sociológo. Por outro lado, ater-se de modo radical à estratégia de flexibilidade - favorecida e reforçada por suas analogias, aliás - foi o que permitiu a Simmel captar problemas que só mais tarde seriam alvo de pesquisas detalhadas, como aqueles relativos à microssociologia, para ficarmos com um dos exemplos mais notáveis.

Refletindo sobre as mesmas questōes, Birgitta Nedelmann (2004) sugere que Weber não teria conseguido elogiar Simmel como sociólogo, mas apenas como artista - evidentemente, não nos interessa se esse elogio é justo ou injusto, mas sim o que revela da concepção que Weber tinha de Simmel, pois não o conhecemos tão bem quanto Weber o conheceu. Parece-me que Nedelmann capta só uma parte do problema, pois também a arte não passa de uma analogia que compõe o projeto filosófico de Simmel, do núcleo goetheano de um projeto em que ele buscava articular Kant e Goethe. Weber apreciava Simmel como filósofo; mais exatamente, como um filósofo com grandes contribuiçóes para a sociologia, como uma personalidade intelectual que, apesar de seu "procedimento que muitas vezes parece "lúdico" e do "modo de tratar as questôes técnicas da ciência" em última análise orientado a "problemas metafísicos e ao sentido da vida", ainda assim teria contribuído, com suas analogias, "mais para o avanço dos interesses de sua disciplina do que somados o fizeram uma porção considerável dos 'catedráticos' em filosofia no padrão que hoje está se tornando usual" (Weber, 1991, p. 11). 


\section{Referências Bibliográficas}

BÁRBARA, Lenin. (2012), Simmel e a analogia: investigaçôes sobre o uso e os aspectos epistemológicos da analogia na Soziologie e na Philosophie des Geldes de Georg Simmel. Dissertação de mestrado. São Paulo, FFLCH-USP.

Blumenberg, Hans. (1987), "An anthropological approach to the contemporary significance of rhetoric". In: BAYNES, Kenneth; BOHMAN, James \& MCCARTHY, Thomas (org.). Philosophy, end or transformation? Cambridge, Miт Press.

CoHn, Gabriel. (1998), "As diferenças finas: de Simmel a Luhmann”. Revista Brasileira de Ciências Sociais, 13 (38): 53-62.

. (2003), Crítica e resignação: Max Weber e a teoria social. São Paulo, Martins Fontes.

Durkheim, Émile. (1970), Sociologia e filosofia. Rio de Janeiro/São Paulo, Forense. . (2004), “The realm of sociology as a science”. In: FrisBY, David (org.). Georg Simmel: critical assessments. Londres/Nova York, Routledge, vol. 2.

Freyer, Hans. (1944), La sociología: ciencia de la realidad. Buenos Aires, Losada.

FRISBY, David. ([1981] 1992), Sociological impressionism: a reassessment of Georg Simmel's social theory. Londres/Nova York, Routledge.

. (2004), Georg Simmel. Londres/Nova York, Routledge.

LuKes, Steven. (1984), Émile Durkheim, su vida y su obra: estudio histórico-crítico. Madri, Centro de Investigaciones Sociológicas/Siglo Veintiuno.

Nedelmann, Birgitta. (2004), “'Psychologism' or sociology of emotions? Max Weber's critique of Georg Simmel's sociology". In: Frisby, David (org.). Georg Simmel: critical assessments. Londres/Nova York, Routledge, vol. 2.

SimmeL, Georg. (1989a), Georg Simmel Gesamtausgabe. Vol. 2: Aufsätze und Abhandlungen 1887-1890; Über sociale Differenzierung; Die Probleme der Geschichtsphilosophie (1892). Frankfurt, Suhrkamp.

. (1989b), Georg Simmel Gesamtausgabe. Vol. 6: Philosophie des Geldes. Frankfurt, Suhrkamp.

. ([1894] 1992a), “Das Problem der Sociologie”. In: Georg Simmel Gesamtausgabe. Vol 5: Aufsätze und Abhandlungen 1894 bis 1900. Frankfurt, Suhrkamp.

. ([1895] 1992b), "Ueber eine Beziehung der Selectionslehre zur Erkenntnistheorie". In: . Georg Simmel Gesamtausgabe. Vol 5: Aufsätze und Abhandlungen 1894 bis 1900. Frankfurt, Suhrkamp.

. ([1908] 1992c), Georg Simmel Gesamtausgabe. Vol. 11: Soziologie: Untersuchungen über die Formen der Vergesellschaftung. Frankfurt, Suhrkamp.

(1995), Georg Simmel Gesamtausgabe. Vol. 10: Philosophie der Mode; Die Religion; Kant und Goethe; Schopenhauer und Nietzsche. Frankfurt, Suhrkamp. 
(1999), Georg Simmel Gesamtausgabe. Vol. 16: Der Krieg und die geistigen Entscheidungen; Grunfragen der Soziologie; Vom Wesen des historischen Verstehens;

Der Konflikt der modernen Kultur; Lebensanchauung. Frankfurt, Suhrkamp. . (2006), Questôes fundamentais da sociologia. Rio de Janeiro, Jorge Zahar. . (2013), “Excurso sobre o problema: como é possível a sociedade?”. Sociologia \& Antropologia, 6 (3): 653-658.

Waizbort, Leopoldo (2000), As aventuras de Georg Simmel. São Paulo, Editora 34. Weber, Max. (1991), "Simmel als Soziologe und Theoretiker der Geldwirtschaft". Simmel Newsletter, 1 (1): 9-13. . (2006), A "objetividade" do conhecimento nas ciências sociais. São Paulo, Ática.

\section{Resumo}

A vida e as formas da sociologia de Simmel

O artigo propõe apreender e analisar o programa sociológico do pensador alemão Georg Simmel (1858-1918), considerado um dos fundadores da sociologia. A análise é orientada por uma leitura atenta das principais analogias de método de que Simmel se serviu em sua tentativa de fundamentar a sociologia como empreitada científica. O objetivo é expor algumas das questôes centrais que informaram o programa sociológico de Simmel, para identificar o que há de peculiar nas respostas que ele oferece a tais questôes.

Palavras-chave: Georg Simmel; Analogia; Fundamentos da sociologia; Pensamento alemão.

\section{Abstract}

Life and forms of Simmel's sociology

In this paper, I seek to grasp and analyze the sociological program of the german thinker Georg Simmel (1858-1918), deemed as one of the founders of german sociology. The analysis will be guided by a close reading of the main methodical analogies that Simmel resorted to in his attempt to give a foundation to sociology as a scientific endeavor. The purpose of this paper is to expose some of the main questions that shaped Simmel's sociological program, in order to identify the distinctive mark of the answers he gave to such questions.

Keywords: Georg Simmel; Analogy; Foundations of sociology; German thought.
Texto enviado em 30/1/2014 e aprovado em 27/2/2014.

Lenin Bicudo Bárbara é doutorando em sociologia na Faculdade de Filosofia, Letras e Ciências Humanas da Universidade de São Paulo. E-mail: leninbicudo@gmail.com. 